\title{
ESTÁGIOS EVOLUTIVOS DA GESTÃO DO CONHECIMENTO
}

\section{EVOLUTIONARY STAGES OF KNOWLEDGE MANAGEMENT}

\author{
Giovana Escrivão ${ }^{1}$; Marcelo Seido Nagano ${ }^{2}$; Charbel José Chiappetta Jabbour ${ }^{3}$ \\ ${ }^{1}$ Universidade de São Paulo - Escola de Engenharia de São Carlos - São Carlos - Brasil \\ giovana@sc.usp.br \\ ${ }^{2}$ Universidade de São Paulo - Escola de Engenharia de São Carlos - São Carlos - Brasil \\ drnagano@usp.br \\ ${ }^{3}$ Universidade de São Paulo - Faculdade de Economia e Administração de Ribeirão Preto - \\ Ribeirão Preto - Brasil \\ charbel@usp.br
}

\section{Resumo}

A abordagem das áreas funcionais das organizações através das fases ou estágios evolutivos possibilita que os gestores identifiquem o nível de maturidade de gestão que determinada área se encontra no desenvolvimento organizacional a fim de elevá-la a um "status" de recurso gerador de vantagem competitiva com participação pró-ativa na gestão estratégica. O objetivo desse artigo é analisar a gestão do conhecimento através da concepção de seus estágios evolutivos nas organizações, possibilitando seu papel estratégico gerador de vantagem competitiva. Como resultado é apresentado uma sugestão de estágios evolutivos para a gestão do conhecimento nas organizações. As limitações da pesquisa remetem ao fato de ser essa pesquisa um ensaio teórico, através da qual foram trabalhadas apenas estruturas conceituais, não gerando, portanto, dados empíricos sobre a evolução da gestão do conhecimento na prática das organizações. Por esses motivos é importante que pesquisas futuras mais detalhadas tenham a possibilidade de aperfeiçoar uma concepção de estágios evolutivos para a gestão do conhecimento na organização.

Palavras-chave: gestão do conhecimento; estágios evolutivos; desenvolvimento organizacional.

\section{Introdução}

Desde a década de 1970, a sociedade tem sofrido uma profunda transformação em sua natureza econômica, social, política e tecnológica que vêm trazendo alterações significativas nas relações e práticas de trabalho (DANTAS, 1999; ZUBOFF, 1994).

Segundo Nonaka e Takeuchi (1997) são vários os autores que denominam este novo período como "sociedade do conhecimento", como, por exemplo, Alvin Toffler, James Brian Quinn, Robert Reich e Peter Drucker.

De acordo com Albagli (1999), entende-se por era do conhecimento, a configuração de um padrão sócio-técnico-econômico, em que as atividades humanas estão baseadas e organizadas em torno das atividades de geração, recuperação e uso de informações e conhecimentos. 
Drucker (1993) afirma ainda que nesta nova economia, o conhecimento não é apenas um recurso ao lado do trabalho, do capital e da terra, mas sim um recurso muito significativo atualmente, talvez o recurso mais significativo.

Com isso, focar o conhecimento como um importante recurso competitivo passou a ser uma nova estratégia para inovar continuamente e enfrentar a instabilidade. Nesse contexto as organizações procuram formas de extrair toda a lucratividade e vantagem competitiva que o conhecimento pode-lhes proporcionar através da gestão do conhecimento (DRUCKER, 1993; NONAKA; TAKEUCHI, 1997; WIIG, 1999).

De acordo com Eisenstat (1996), para que uma área organizacional apóie a estratégia da organização ela precisa entender suas fontes de vantagem competitiva através do conhecimento dos estágios de cada área, suas características, problemas e necessidades. Apesar das teorias aqui tratarem sobre desenvolvimento organizacional e áreas funcionais da organização é preciso ressaltar que a gestão do conhecimento não é considerada uma área funcional da organização, pois ela é considerada como permeando toda a organização.

Estudar os estágios evolutivos das áreas da organização possibilita ações direcionadas às necessidades, aos sistemas e a soluções específicas para cada estágio. Isso traz um desenvolvimento de cada função coerente com o desenvolvimento organizacional, fazendo dessas áreas recursos contribuintes à estratégia global da organização e geradores de vantagem competitiva com um papel pró-ativo na estratégia da organização (DAFT, 2003; EISENSTAT, 1996; HAYES; WHEELWRIGHT, 1984; MESHOULAM; BAIRD, 1987; SANTOS, 2000; SANTOS 2001; SCHULER; JACKSON, 1995).

Diversos trabalhos propõem o estudo dos estágios evolutivos das várias áreas de gestão das organizações como recursos humanos (MESHOULAM; BAIRD, 1987), produção (HAYES; WHEELWRIGHT, 1984), logística (BOWERSOX, 1986) e qualidade (GARVIN, 1992), entre outras. Entretanto, isso não tem ocorrido com a gestão do conhecimento, a qual, é necessário ressaltar, não se encaixa na categoria de área funcional de uma organização, pois a gestão do conhecimento está presente em toda a organização.

Assim surge a necessidade de estudar a gestão do conhecimento através de seus estágios de evolução, proporcionando um melhor entendimento dos problemas e das necessidades dessa área do saber gerencial em cada estágio de seu desenvolvimento organizacional, possibilitando ações e o uso de ferramentas e sistemas mais adequados às necessidades exigidas em cada momento, possibilitando a ascensão da gestão do conhecimento para o estágio posterior, e assim, tornando-se um recurso gerador de vantagem competitiva para a organização através de um papel pró-ativo à estratégia organizacional (SANTOS, 2001; RODRIGUES; SANTOS; NAGANO, 2004; CRUZ; NAGANO, 2006). 


\section{Gestão do Conhecimento}

A busca pela lucratividade e pelo sucesso organizacional levou a criação de um grande número de teorias administrativas. Inicialmente, a administração científica e o taylorismo surgem com uma visão racionalista do trabalho. Posteriormente a administração das relações humanas apresenta uma abordagem humanística da administração. Após novas considerações, o ambiente passou a ser introduzido no processo de tomada de decisão. Com novos estudos conclui-se que diferentes contextos pedem diferentes abordagens e que todas as teorias administrativas trazem sua contribuição, conforme a teoria da contingência. Apesar disso, a busca incessante pela lucratividade cria continuamente novas teorias (FERREIRA, 2003).

No contexto contemporâneo, em que o conhecimento é um importante recurso de produção, as estratégias competitivas passaram a fazer da informação a base de suas formulações, aumentando a importância da gestão do conhecimento (TERRA et al., 2007). Assim, as organizações passam a se preocupar com a criação do conhecimento organizacional e começam a surgir estudos sobre o tema na área científica (CHEN; CHEN, 2005).

Por mais simples que possa parecer, é importante diferenciar os conceitos: dado, informação e conhecimento.

De acordo com Davenport e Prusak (1998), dados são apenas registros; informações são dados estruturados de maneira que forme uma "mensagem" e; conhecimento é um conjunto de experiências, valores e informações contextuais, complexas e estruturadas formalmente originadas na mente das pessoas e armazenado organizacionalmente não somente em documentos, mas também em rotinas, processos e normas da organização. Conhecimento diz respeito a crenças e compromissos, diferente da informação; ele está relacionado a uma ação, a informação não. $\mathrm{O}$ conhecimento é contextual e relacional.

Para Terra (2007), gerir o conhecimento é organizar tecnologia, políticas, processos e ferramentas gerenciais visando à identificação, a geração, o compartilhamento e a disseminação do conhecimento organizacional e estratégico.

Segundo Davenport e Prusak (1998), organizações saudáveis usam e geram conhecimento ao interagirem com seus ambientes. Sem conhecimento as organizações não poderiam se organizar e manterem-se em funcionamento.

Com a globalização e a disseminação de tecnologias, muitos acreditam na fácil transferência de conhecimento, mas nem todo conhecimento pode ser facilmente transferível. O conhecimento nem sempre é facilmente transferível porque muitas vezes ele ou parte dele está enraizado nas pessoas e organizações, permanecendo específicos e não-compartilhados. Daí se vê a necessidade de novos esforços no sentido de estimular não somente a geração, mas também a difusão de novos 
conhecimentos (LEMOS in LASTRES, 1999).

\begin{abstract}
"Segundo Drucker (1999), o grande desafio das organizações é identificar e promover a mudança contínua, consistindo em rever criticamente o conhecimento antigo e criar o novo... Esta afirmação de Drucker (1999), se feita algum tempo atrás, certamente conduziria a um maior investimento sobre os recursos tecnológicos. Entretanto, passadas algumas décadas da difusão dos recursos da informática, o foco sobre a formação do capital humano ficou ainda mais evidente nos dias de hoje. Os trabalhadores de uma organização formam a sua estrutura. Portanto, o desafio das empresas de hoje é formar e integrar uma boa equipe de trabalho com conhecimento, capacidade e habilidades específicas para os postos de trabalho, para cumprirem as tarefas exigidas e para pensarem estrategicamente sobre os destinos da organização" (BASSANI; NIKITIUK; QUELHAS, 2003).
\end{abstract}

Embora as tecnologias tenham um potencial enorme para facilitar o aprendizado, elas são apenas instrumentos que propiciam a criação, o armazenamento e a transferência do conhecimento. São as pessoas quem criam e transmitem conhecimentos. Por estar enraizado nas pessoas, o conhecimento muitas vezes permanece no indivíduo, não sendo compartilhado. Os investimentos realizados pela maioria das organizações modernas no desenvolvimento de sistemas de informação são quase que exclusivamente direcionados para a tecnologia em si, e pouco para as informações, para as pessoas e seus conhecimentos, assim como para o conhecimento e à cultura organizacional (ALVARENGA NETO; BARBOSA; PEREIRA, 2007; LEMOS, 1999).

\title{
2.1 Teoria da criação do conhecimento
}

Há dois tipos de conhecimentos, o conhecimento explícito, aquele que pode ser colocado em papel, expresso em forma de orações ou desenhos; e o tácito, vinculado aos sentidos, a percepção individual, a capacidade de expressão corporal, um conhecimento de difícil transmissão (VON KROG; ICHIJO; NONAKA, 2001).

A teoria da criação do conhecimento de Nonaka foi desenvolvida baseada no sucesso das empresas japonesas, o qual se deve a capacidade e especialização destas na "criação do conhecimento organizacional” (NONAKA; TAKEUCHI, 1997).

Diferentemente das organizações ocidentais, que vêem a organização como máquina processadora de informações enxergando somente o conhecimento explícito, a abordagem das empresas japonesas apesar de reconhecer o conhecimento explícito, vê o conhecimento como algo basicamente tácito, pessoal, dificilmente visível, exprimível e transmissível, enraizado nas ações e experiências de um indivíduo, tais como suas emoções, valores e ideais, incluindo insights e palpites (NONAKA; TAKEUCHI, 1997).

O conhecimento tácito pode ser segmentado em duas dimensões: a dimensão técnica, um tipo de capacidade informal e de difícil definição, o chamado know-how, experiência adquirida ao longo dos anos, mas de difícil articulação e; a dimensão cognitiva, esquemas, modelos mentais, crenças e percepções tão arraigadas que as tomamos como certas, ela reflete nossa visão "das 
coisas". Ele é um tipo de conhecimento que vem da experiência direta, enfatizada pelos japoneses através da tentativa e erro. Já o conhecimento explícito pode ser facilmente processado por computadores, transmitidos eletronicamente e armazenado em bancos de dados (NONAKA; TAKEUCHI, 1997).

Segundo Nonaka (1994) para que o conhecimento organizacional seja criado é preciso convertê-lo em conhecimento explícito. O ponto principal da teoria da criação do conhecimento está na mobilização e na conversão do conhecimento tácito. Daí surge o "motor" do processo de criação do conhecimento desta teoria, que é a conversão do conhecimento, através de quatro modos (socialização, externalização, combinação e internalização) e pelo qual o conhecimento individual é "amplificado" na organização. Esse processo de transformação do conhecimento é conhecido como modelo SECI de criação do conhecimento.

A criação do conhecimento é um processo contínuo de interação dinâmica entre o conhecimento tácito e o conhecimento explícito: as quatro modalidades do conhecimento interagem na espiral do conhecimento, ou seja, no modelo SECI. Com o movimento ascendente (para cima) nos níveis organizacionais a espiral torna-se "maior", que pode gerar novas espirais do conhecimento. Isso deve ocorrer em um contexto capacitante que possibilite criar, utilizar, compartilhar e disseminar o conhecimento: o chamado Ba. Esse contexto organizacional pode ser físico, virtual e/ou mental (NONAKA; TAKEUCHI, 1997; VON KROGH; ICHIJO; NONAKA, 2001).

Os autores sugerem três características-chave para a criação do conhecimento. A linguagem figurada, da metáfora e da analogia para expressar intuições e insights, fazendo com que indivíduos fundamentados em diferentes contextos e com diferentes experiências compreendam algo intuitivamente através de símbolos, compartilhando o conhecimento pessoal para que tenha sentido para outras pessoas e possa ser transmitido à organização através de discussões, diálogos e debates em grupo. E a ambiguidade e a redundância, de onde nascem novos conhecimentos ao estimular o diálogo frequente e a comunicação e ao criar uma "base cognitiva comum" entre os funcionários (NONAKA; TAKEUCHI, 1997).

Quanto aos agentes na criação do conhecimento tem-se que não há um único departamento ou grupo de especialistas com responsabilidade exclusiva pela criação do novo conhecimento. A criação do conhecimento é produto da interação entre todos na organização, assim, funcionários da linha de frente, gerentes de nível médio e gerentes seniores, cada um deve fazer a sua parte (NONAKA; TAKEUCHI, 1997).

De acordo com a teoria da criação do conhecimento de Nonaka (NONAKA; TAKEUCHI, 1997; NONAKA, 2000) há alguns requisitos para se criar, armazenar e disseminar o conhecimento organizacional: 
O conhecimento organizacional é criado através da interação entre duas formas de conhecimento: os conhecimentos tácito e explícito. Essa interação, chamada de "conversão do conhecimento" é um processo "social” entre indivíduos, e não confinada dentro de um indivíduo.

Essa transformação ocorre de forma interativa e em espiral. Há quatro formas de conversão destes: a socialização (conversão do conhecimento tácito em conhecimento tácito, o qual é um processo de compartilhamento de experiências que envolvem trabalho em grupo e experiência prática); a externalização (conversão do conhecimento tácito em conhecimento explícito, o qual é um processo de criação do conhecimento perfeito através do diálogo e do uso de metáforas e analogias); a combinação (conversão do conhecimento explícito em conhecimento explícito, que é um processo de sistematização de conceitos em sistema de conhecimento, no qual, conceitos são formados pelas equipes através da combinação de dados); e a interação (conversão do conhecimento explícito em conhecimento tácito, que é o processo de incorporação do conhecimento explícito no conhecimento tácito, internalizando o novo conhecimento explícito compartilhado na organização pelos indivíduos).

Primeiramente o processo de socialização desenvolve um "campo" de interação, facilitando o compartilhamento de experiências. Segundo, o processo de externalização ocorre através da reflexão coletiva e do diálogo com uso de metáfora e analogia. Em um terceiro momento, uma rede de interação entre o conhecimento recém-criado e o conhecimento já existente provoca o processo de combinação. E, finalmente, o processo de internalização ocorre através do "aprender fazendo".

Cada processo gera um tipo de conhecimento diferente. A socialização gera o conhecimento compartilhado (modelos mentais, por exemplo); a externalização gera o conhecimento conceitual (criação de um conceito através de metáforas e analogias); a combinação produz o conhecimento sistêmico (geração de protótipos, por exemplo); e a internalização dá origem ao conhecimento operacional (experiência prática). Assim, percebe-se que a criação do conhecimento organizacional é um processo de interação contínua e dinâmica entre o conhecimento tácito e o conhecimento explícito e esse processo se da na forma de um espiral.

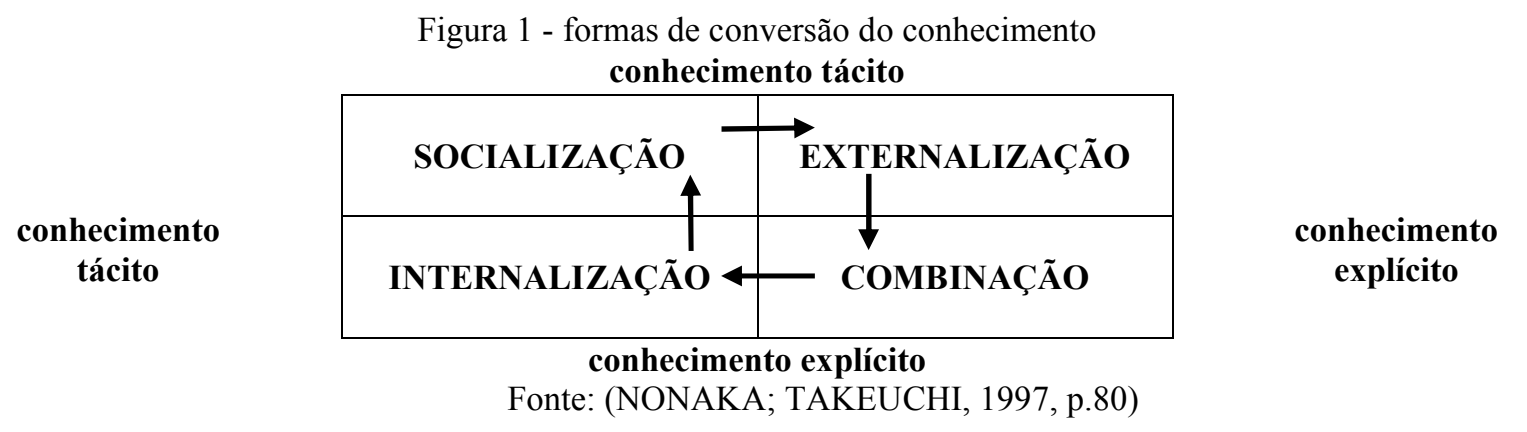

Outro requisito é a necessidade de que se crie conhecimento organizacional, impedindo que o conhecimento seja mantido apenas no âmbito individual. É o indivíduo quem cria o conhecimento 
e não a organização, mas se essa informação não for transmitida à organização mantendo-se somente em nível individual, ela será perdida e não constará como uma informação pertencente à organização. É necessário tomar conhecimento das informações individuais e transmiti-las à organização para que essas informações possam ser usadas pela organização.

A organização deve oferecer condições capacitadoras necessárias para que o indivíduo, no grupo, crie conhecimento organizacional. Ela deve fornecer o contexto apropriado facilitando as atividades em grupo e a criação e o acúmulo de conhecimento em nível individual, através de cinco condições: intenção organizacional, que pode ser definida como a aspiração de uma organização às suas metas; autonomia aos membros da organização, o que introduz oportunidades inesperadas e possibilita a automotivação dos indivíduos para a criação de conhecimento; flutuação e caos criativo, que estimulam a interação entre a organização e o meio ambiente externo, possibilitando a exploração da ambiguidade, da redundância e dos ruídos dos sinais ambientais, aprimorando seu sistema de conhecimento; redundância, ou seja, informações que transcendem as exigências operacionais imediatas dos membros da organização, aumentando o volume de informações a serem processadas e; variedade de requisitos dos membros da organização, o que facilita que se enfrentem diferentes situações. Assim, a criação do conhecimento organizacional envolve cinco fases: primeiramente o compartilhamento do conhecimento tácito; a criação de conceitos; seguida da justificação de conceitos; a construção de protótipos; e a nivelação do conhecimento (VON KROG; ICHIJO; NONAKA, 2001).

O processo por meio do qual ocorre a criação do conhecimento é um processo não-linear e interativo, possuindo cinco fases: compartilhamento do conhecimento através da interação; criação do conceito, que envolve diálogo e reflexão coletiva; justificativa do conceito, uma espécie de filtragem; construção do arquétipo, transformação de um conceito em algo tangível, concreto; e difusão interativa, ou seja, uma atualização contínua.

O modelo gerencial que facilita a criação e difusão do conhecimento é uma síntese dos dois modelos gerenciais dominantes, os modelos top-down (de cima para baixo) e bottom-up (de baixo para cima). O modelo gerencial middle-up-down (do meio para cima e para baixo) coloca o gerente de nível médio no centro da gestão do conhecimento e redefine o papel da alta gerência e dos funcionários da linha de frente. Assim, a gerência de nível médio resolve a contradição entre o que a alta gerência espera criar (que normalmente são visões sonhadoras) e o que realmente existe no mundo real (visão dos funcionários de linha de frente).

Assim como há um modelo gerencial que facilita a criação e a transmissão do conhecimento, há uma estrutura que também o faz. É a estrutura em hipertexto, que é a combinação de dois tipos básicos de estrutura, a burocracia e a força-tarefa. Uma estrutura não-hierárquica e auto-organizada que funcione em conjunto com sua estrutura hierárquica formal. É um sistema 
aberto que interage com o ambiente externo. Uma organização em hipertexto é constituída em níveis pelos quais seus membros podem mudar de contexto: o sistema de negócios, no qual são realizadas as operações normais de rotina; a equipe de projeto, no qual várias equipes de projeto se engajem em atividades criadoras do conhecimento; e a base de conhecimento, no qual o conhecimento organizacional gerado nos dois níveis superiores é recategorizado e recontextualizado.

E, finalmente, a organização deve integrar os méritos de cada uma das duas metodologias existentes, a ocidental e a japonesa.

Desses requisitos necessários ou critérios facilitadores para que a organização crie conhecimento, surgem algumas implicações práticas:

- Criar uma visão de conhecimento e comunicá-la internamente na empresa;

- Desenvolver uma equipe de conhecimento;

- Construir um campo de interação de alta densidade (ambiente no qual ocorrem intensas interações entre os membros da equipe) na linha de frente;

- Pegar carona no processo de desenvolvimento de novos produtos, portanto um processo adaptativo, flexível, interativo, dinâmico e contínuo.

- Adotar o modelo gerencial middle-up-down;

- Adotar como estrutura a organização em hipertexto e;

- Construir uma rede de conhecimento com o mundo externo.

Esses requisitos e práticas criam um ambiente propício a uma gestão do conhecimento efetiva.

\section{Desenvolvimento organizacional e estágios evolutivos}

Existem diversas teorias e autores que discutem o desenvolvimento organizacional e os estágios evolutivos, sendo aqui descritas três dessas teorias. Duas delas referem-se ao desenvolvimento organizacional: as fases do desenvolvimento organizacional proposta por Greiner (1986) e o ciclo de vida das organizações de Daft (2003). Existem outros trabalhos que propõem estágios evolutivos das áreas de gestão, os quais foram sintetizados em Santos (2001), apresentado como uma terceira teoria.

\subsection{Fases de evolução e revolução das organizações de Greiner (1986)}

Segundo a teoria de Greiner (1986), há cinco fases de crescimento. Greiner (p. 106, 1986) ressalta a importância do conhecimento e entendimento dessas fases, pois "cada fase é ao mesmo tempo um efeito da fase anterior e uma causa da fase seguinte".

O autor define cinco conceitos que considera essenciais na elaboração de um modelo de 
desenvolvimento organizacional: idade da organização: é o tempo de existência da organização; porte da organização: é o tamanho da organização; estágios de evolução: são os períodos "calmos", sem contratempos e com necessidades apenas de ajustes menores, pelos quais a organização passa; estágios de revolução: são os períodos "turbulentos", de crise, de agitação pela inadequação dos métodos antigos de administração e com necessidade de ajustes maiores, pelos quais a organização passa; ritmo de expansão da indústria: é o ritmo pelo qual a organização passa pelas diversas fases de evolução e revolução dependendo da indústria em que se encontra.

Segundo o autor, todos esses fatores influenciam na elaboração de um modelo de desenvolvimento organizacional, pois se apresentam de forma diferente em cada fase organizacional. Assim sendo, as cinco fases de expansão propostas por ele são:

- Fase 1 - Criatividade: Atenção concentrada na criação de um produto ou serviço e no mercado consumidor; foco nas atividades técnicas e certo desprezo pelas atividades administrativas; comunicação entre empregados freqüente e informal; longos períodos de trabalho, salários modestos e promessa de participação; controle de atividades baseado na coleta imediata de informações do mercado e conforme reação dos clientes. Com certo crescimento surge uma crise administrativa, os administradores ficam sobrecarregados de atividades e surge a consequente necessidade de algumas mudanças, faz-se necessário contratar novos administradores.

- Fase 2 - Direção: Fase de expansão contínua; criação de uma estrutura organizacional e cargos mais especializados; introdução de métodos contábeis para manutenção e controle de estoques e compras; adoção de incentivos, orçamentos e normas de trabalho; comunicação mais formalizada e impessoal; separação entre as atividades administrativas, especialistas e operacionais. O surgimento de exigências de maior poder por parte dos gerentes de nível médio gera uma crise de autonomia, sendo necessário aumentar a delegação de poderes.

- Fase 3 - Delegação: Surge com a descentralização da estrutura; maior responsabilidade aos superintendentes de fábrica e diretores regionais; uso métodos de cálculos de venda e bonificação como motivação; administração baseada em relatórios periódicos sobre as equipes; novas incorporações; comunicação da alta direção para com as filiais é pouco freqüente e restrita. A descentralização e a liberdade geram uma crise de controle por parte dos diretores, o que leva a necessidade de adoção de novas técnicas de coordenação de esforços.

- Fase 4 - Coordenação: Uso de sistemas formais para a coordenação das atividades; fusão de unidades descentralizadas e grupos de produtos ou serviços; formalização dos processos de planejamento; criação de programas e revisão administrativa e contratação de novos funcionários para tal; avaliação de investimentos; equilíbrio entre centralização e descentralização das funções técnicas; compra de ações e distribuição de lucros como forma de promoção da organização. A proliferação de sistemas de controle e programas administrativos leva a uma crise burocrática, 
assim a organização deve promover forte colaboração pessoal amenizando a rigidez e a formalidade dos sistemas.

- Fase 5 - Colaboração: Formação de equipes, controle social e autodisciplina; rápida solução de problemas através da ação conjunta; atividade em grupo; redução do número de especialistas do escritório central que agora terão como função consultar as equipes e não dirigi-las; simplificação dos sistemas existentes; reuniões freqüentes entre os principais administradores para tratar as questões mais graves; programas educacionais e treinamentos voltados ao trabalho em equipe. Quanto a crise que possa surgir nessa fase o autor sugere uma saturação psicológica dos funcionários que poderá ser resolvida com novas estruturas e programas que permitam descanso, reflexão e recuperação dos funcionários.

\subsection{Ciclo de vida das organizações de Daft (2003)}

A teoria do ciclo de vida das organizações sugere que as organizações nascem, envelhecem e eventualmente morrem, em estágios sequenciados naturalmente (DAFT, 2003). Há uma diferença essencial com a teoria anterior, pois, Greiner (1986) associa o passar do tempo com o crescimento permanente das organizações, sendo que a mortalidade está ausente. Se a organização tem conhecimento do estágio em que se encontra e do estágio para o qual ela pretende se direcionar futuramente, ela saberá o que é importante durante cada fase, como ela deve agir atual e futuramente (DAFT, 2003).

De acordo com Daft (2003), o ciclo de vida das organizações compreende os seguintes estágios:

- Estágio Empreendedor: É a fase de nascimento de uma organização, na qual a preocupação maior está na criação de um único produto ou serviço e na sua sobrevivência, por isso há maior dedicação às áreas técnicas de produção e marketing. Seu crescimento ocorre com a inovação de um produto já existente ou com a criação de um novo produto. A organização é pequena, sua estrutura é informal, não burocrática, centralizada com controle baseado na supervisão dos donos. Com o crescimento da organização há um aumento do número de funcionários e isso muitas vezes não é levado em consideração já que a preocupação dos dirigentes se concentra sobre a fabricação, criação e venda de produtos ou serviços existentes ou novos, gerando uma crise de liderança, o que torna necessário adquirir novos gerentes para lidar as mudanças características desse crescimento.

- Estágio de Coletividade: Aqui se procura diferenciar o produto principal. Sua maior meta é o crescimento contínuo. Novos departamentos são estabelecidos seguindo uma hierarquia de autoridade. Surge uma divisão inicial do trabalho e são dadas atribuições a cada cargo. A estrutura, o controle e a comunicação são ainda muito informais, apesar do surgimento inicial de alguns 
sistemas formais. Com o sucesso da organização os funcionários dos níveis mais baixos passam a se sentir constrangidos com a forte liderança de cima para baixo e os gerentes de linha passam a exigir mais liberdade de ação ao mesmo tempo em que os gerentes de alto nível não querem delegar responsabilidade, o que gera uma crise de autonomia. Devido a essa necessidade de delegação a alta administração deve encontrar mecanismos de controle e coordenação que irão além da supervisão direta da cúpula.

- Estágio de Formalização: Surgem as características burocráticas, a formalização de procedimentos, o claro estabelecimento de hierarquia e divisão do trabalho com o uso de normas e sistemas de controle, apesar de ainda existir a necessidade da alta administração de delegar a autoridade. São criados sistemas de incentivos. A comunicação é pouco frequente. A meta principal é manter a estabilidade interna e expandir o mercado de atuação com base na criação de uma linha de produtos, para isso há um departamento responsável pela pesquisa e desenvolvimento, trazendo assim a inovação. A preocupação com as operações deixa de ser a principal preocupação, voltando seu foco para questões de estratégia e planejamento. O excesso de formalidades pode asfixiar os executivos de nível médio, os quais podem também se ressentir quanto a intrusão do pessoal de assessoria. A organização torna-se muito grande e complexa para ser gerenciada por sistemas formais.

- Estágio de Elaboração: Estágio típico de uma organização grande, madura e burocrática, com extensos sistemas de controle, normas e procedimentos. Os gerentes podem solucionar o excesso de formalidade com a formação de equipes de trabalho formadas por pessoas de diferentes áreas e/ou divisões da organização, os sistemas formais são então simplificados e substituídos por equipes de gerentes e forças-tarefas. Quanto à inovação, ela é institucionalizada mediante um departamento de pesquisa e desenvolvimento. Aqui já se têm múltiplas linhas de produtos ou serviços.

\subsection{Estágios evolutivos das áreas funcionais de Santos (2001)}

O estudo de Santos (2001) sobre a caracterização e a relação entre os estágios evolutivos das áreas de recursos humanos e da produção baseado nas abordagens de diversos autores ${ }^{1}$ e nas configurações organizacionais de Mintzberg (1995) apresenta os seguintes estágios evolutivos organizacionais:

- Estágio 1 - Nesse estágio ocorre a iniciação funcional de recursos humanos. Durante a iniciação funcional da gestão de recursos humanos a principal preocupação da área está sobre o recrutamento, a seleção e a remuneração do pessoal. Nessa fase a área de recursos humanos atua

\footnotetext{
${ }^{1}$ Eisenstat (1996), Bowersox; Closs; Helferich (1986), Garvin (1992), Hayes; Wheelwright (1984), Meshoulam; Baird (1987), Schuler; Jackson (1995).
} 
apenas na prevenção de problemas como alta rotatividade, conflitos entre a organização e sindicatos, governos, assumindo responsabilidade por atividades operacionais para que a gerência possa se concentrar nos problemas críticos da gestão de negócios. Quanto à produção essa fase é caracterizada pela neutralidade interna em relação à estratégia empresarial.

- Estágio 2 - Para a área de recursos humanos, nessa fase surgem novos sistemas de armazenamento de dados, especialização técnica, há um crescimento das atividades funcionais, as estruturas e os processos são formais, o recrutamento e a seleção passam a tornarem-se atividades especializadas e passam a ser comandadas por especialistas e a área de recursos humanos não está mais restrita apenas a prevenção de problemas, pois agora ela passa a gerenciar as relações externas. Enquanto que a produção é caracterizada pela neutralidade externa da produção em relação à estratégia empresarial. Torna-se comum comparar o desempenho da produção com os principais competidores do setor industrial.

- Estágio 3 - O gerenciamento dos recursos humanos passa a ser feito dentro de cada divisão. Com a integração funcional e a diversificação de produtos há uma certa descentralização e integração dos recursos humanos dentro das funções. A gestão de recursos humanos está orientada para a coordenação e integração das sub-funções de pessoal como treinamento, recrutamento e seleção. Mas esse avanço todo está restrito as divisões, pois nessa fase a área de recursos humanos ainda não participa efetivamente do processo de planejamento estratégico. A produção passa a apoiar internamente a estratégia empresarial. A gerência reconhece o valor da estratégia de produção e emprega instrumentos como organograma e declaração de missão. A integração entre a gestão da produção e a alta gerência é unidirecional, portanto, o papel da produção é apenas apoiador, não intervindo na estratégia organizacional.

- Estágio 4 - Nesse estágio ocorre a inserção da área de recursos humanos na gestão da organização. A gerência de recursos humanos assume uma postura pró-ativa de envolvimento com a organização e com isso surge a necessidade de capacitação dos profissionais da área. A gestão da produção apóia externamente a estratégia da organização, assim, ela passa a estabelecer vantagens competitivas e a definir metas estratégicas.

Com base nas similaridades dos vários estágios evolutivos das áreas de gestão de recursos humanos e de produção, Santos (2001) propõe a existência de quatro estágios organizacionais para as áreas de gestão:

- Iniciação Funcional: Inexistência de estratégia empresarial formalizada; Criação das atividades funcionais; Inexistência de áreas funcionais.

- Especialização Funcional: Neutralidade estratégica; Prevenção de problemas para a consecução da estratégia empresarial; Adoção das melhores práticas; Criação das áreas funcionais; Foco no conteúdo. 
- Integração Interna: Atuação funcional baseada em objetivos definidos; Conscientização da estratégia empresarial; Foco no contexto interno.

- Integração Externa: Efetiva participação na gestão de negócios; Realização de diagnóstico do ambiente competitivo; Caráter inter-funcional das atividades funcionais e dos programas de inovação; Foco no contexto externo.

\subsection{Análise comparativa das propostas}

Para melhor visualização e análise é apresentada uma tabela que sintetiza os estágios funcionais ou organizacionais, apenas pelo nome, os quais representam a característica principal de cada estágio, de acordo com os autores estudados:

TABELA 1 - Síntese dos estágios segundo autores estudados

\begin{tabular}{|c|c|c|c|c|c|}
\hline $\begin{array}{c}\text { Estágio/ } \\
\text { Autor }\end{array}$ & Estágio I & Estágio II & Estágio III & Estágio IV & Estágio V \\
\hline Greiner & criatividade & direção & delegação & coordenação & colaboração \\
\hline Daft & empreende-dor & coletividade & formalização & elaboração & - \\
\hline Santos & $\begin{array}{c}\text { iniciação } \\
\text { funcional }\end{array}$ & $\begin{array}{c}\text { especialização } \\
\text { funcional }\end{array}$ & $\begin{array}{c}\text { integração } \\
\text { interna }\end{array}$ & $\begin{array}{c}\text { integração } \\
\text { externa }\end{array}$ & - \\
\hline
\end{tabular}

Fonte: Autoria própria (2008)

\section{O que a gestão do conhecimento pode aprender com os estágios evolutivos?}

\subsection{Relevância da concepção dos estágios evolutivos da gestão do conhecimento}

Há um grande valor sobre o papel do conhecimento na sociedade atual, o qual, com o auxílio da tecnologia da informação, veio substituir o papel do capital monetário do século passado, quando a posse de terra, de instalações, de máquinas e da mão-de-obra trazia certa vantagem competitiva a uma organização em relação a seus competidores (DRUCKER, apud NONAKA, 1993; WREN, 1994). Atualmente possuir instalações físicas e ter propriedade sobre a mão-de-obra, capacidade de fabricação, acesso ao capital de baixo custo e relações de cooperação com clientes, fornecedores e governos não são mais requisitos suficientes para manter uma posição estável no mercado meio a tantos concorrentes. Com o advento da globalização e, consequentemente, o surgimento de clientes mais exigentes, competidores e fornecedores mais sofisticados que implementam inovações continuamente, torna-se cada vez mais necessário saber gerenciar um novo recurso: o conhecimento.

Mas apenas obter o conhecimento necessário à organização não a eleva a uma posição vantajosa no mercado. Mais do que adquirir esse recurso, é preciso gerenciá-lo da melhor forma possível, identificando as fontes de geração do conhecimento na organização, trabalhando-o, o disseminado, e principalmente, criando novo conhecimento, de forma que toda a organização possa 
ter acesso e fazer uso dele gerando vantagem competitiva à organização. Segundo Wiig (1999, p. 4) "a meta da gestão do conhecimento é construir e explorar a efetividade e a lucratividade do capital intelectual".

Dessa forma, identificar e definir as fases ou estágios pelos quais a gestão do conhecimento passa em seu desenvolvimento na organização pode proporcionar um melhor entendimento dos problemas e necessidades da área em cada estágio de seu desenvolvimento organizacional, possibilitando ações e o uso de ferramentas e sistemas mais adequados às necessidades exigidas em determinado momentos e circunstâncias, possibilitando a ascensão da gestão do conhecimento para o estágio posterior, e assim, tornar-se um recurso competitivo ao lado das outras áreas da organização que já assumem uma postura de recurso gerador de vantagem competitiva para a organização através de um papel pró-ativo, gerando vantagem competitiva à estratégia organizacional (Santos, 2001; Rodrigues; Santos; Nagano, 2004; Cruz; Nagano, 2006).

\subsection{Proposição dos estágios evolutivos da gestão do conhecimento}

A análise evolutiva da gestão do conhecimento revela que o início dos estudos sobre esse tema emerge das diversas mudanças trazidas com a globalização e com a difusão da tecnologia, principalmente no início da década de 1980. Mas é somente a partir de 1995 com o lançamento do livro de Nonaka e Takeuchi que a gestão do conhecimento passa a ser um tema discutido com frequência no meio acadêmico (CHEN; CHEN, 2005; PRUSAK, 2001).

Apesar disso, suas raízes e origens são muito antigas, pois a gestão do conhecimento tem como base o conhecimento e a informação, conceitos que se originaram de diversas fontes como o pensamento abstrato filosófico (para entender o papel e a natureza do conhecimento), na psicologia (para entender o papel do conhecimento no comportamento humano), na economia e nas ciências sociais (para entender o papel do conhecimento na sociedade) e, mais recentemente, nas teorias de negócios (para entender o conhecimento nas organizações e no trabalho) (Wiig, 1999).

Desta forma, pode-se propor o seguinte desenvolvimento:

TABELA 2 - Proposição dos estágios evolutivos da gestão do conhecimento

ESTÁGIO 1: Coleta de informação; Comunicação informal; Coordenação pessoal; Coleta de informações não sistemática

ESTÁGIO 2: Coleta classificação e armazenamento de dados e informações de forma sistemática

(uso de bases de dados e relatórios); Conhecimento concentrado na cúpula; Limitado a aquisição de ferramentas tecnológicas, não integração, nem disseminação do conhecimento

ESTÁGIO 3: Reconhecimento do conhecimento tácito; Integração e disseminação do conhecimento

ESTÁGIO 4: Foco na aprendizagem organizacional e no trabalho em equipe; Captação do conhecimento interno e externo; Integração e disseminação do conhecimento na busca da criação de

Fonte: Autoria própria (2008) novos conhecimentos 
- Inicialmente a gestão do conhecimento fica restrita ao dirigente da organização que é muito pequena para ter sistemas formais de informação, assim a comunicação é informal. Pode-se dizer que a estrutura simples permite uma coordenação por contato pessoal do dirigente com os funcionários. O conhecimento do negócio está na cabeça do empreendedor e não há compartilhamento com outras pessoas e nem participação dos funcionários. Restringe-se à coleta de informações (clientes, mercado) de forma não sistemática.

- No estágio seguinte, é feito o armazenamento dos dados e da informação (conhecimento explícito) de forma sistemática em bases de dados e na criação de relatório de informações e análise destes. O pouco conhecimento existente fica concentrado na cúpula da organização, não há ainda integração e muito menos disseminação do conhecimento. Nessa etapa a gestão do conhecimento é limitada a aquisição de ferramentas tecnológicas. Muitas organizações erram em estacionar já nessa primeira etapa ao pensar que somente adquirir essas ferramentas e manter o conhecimento organizado em bases de dados e programas é suficiente, ou seja, restringemse a coleta, classificação e armazenamento de dados, informações e conhecimentos;

- Com a emergência crescente da gestão do conhecimento é dada grande ênfase ao indivíduo e é reconhecido seu poder de contribuição à organização através de suas experiências, suas crenças e seus valores. Com a percepção da necessidade de se adquirir e reter esse conhecimento passa-se a considerar o conhecimento tácito, um conhecimento subjetivo e de difícil transmissão até então pouco estudado. Assim o conhecimento é captado apenas internamente. O conhecimento passa a concentrar-se nos especialistas e ainda não é integrado e nem disseminado pela organização;

- Percebe-se então que apenas adquirir esse conhecimento é insuficiente para a organização, pois de nada adianta adquiri-lo se ele se "perde" ou "fica parado" sem uso efetivo para a organização, é preciso disseminá-lo por toda a organização. Aqui, o conhecimento, já integrado, passa a ser disseminado entre os indivíduos da organização, mas continua sendo captado apenas internamente (funcionários). Estabelece-se uma estrutura para a organização adquirir, reter e disseminar esse conhecimento, através de medidas como contratação de pessoal novo, seu treinamento e criação de novos processos;

- Com todos os indivíduos da organização tendo acesso ao conhecimento surge a necessidade de trabalhar o aprendizado individual e, principalmente, o aprendizado em grupo e o trabalho em equipes para que o conhecimento seja compartilhado possibilitando a criação de novos conhecimentos. O foco agora se volta para a aprendizagem organizacional. Novas mudanças ocorrem na estrutura da organização como, por exemplo, uma remuneração que recompense o trabalho em equipe mais do que o trabalho individual e que vise motivar a inovação e a criação de novos conhecimentos e uma estrutura menos hierárquica e com menor controle, que incentive a 
participação e a opinião de cada funcionário. O conhecimento é captado interna e externamente, integrado, disseminado e, finalmente, trabalhado para que através de uma estrutura específica e do uso de alguns instrumentos, propicie e incentive a criação de novos conhecimentos.

Assim, a evolução da gestão do conhecimento que inicialmente se restringe a obtenção de dados; seguindo para uma sistematização dessas informações (conhecimento explícito); para em etapas subsequentes focar o indivíduo e começar a reconhecer a importância de seu conhecimento, seus valores, sua idéias (conhecimento tácito); disseminando o conhecimento por toda a organização para que todos possam fazer uso dele e; finalmente, promovendo a aprendizagem organizacional e a criação do conhecimento, pode contribuir para uma gestão do conhecimento efetiva geradora de vantagem competitiva à estratégia organizacional.

Portanto, pode-se observar, conforme o quadro abaixo, que a organização, em seu estágio inicial, não apresenta ainda mecanismos de articulação da gestão e criação do conhecimento. Em seu segundo estágio, a organização passa a desenvolver alguns fatores da organização que propiciam, mesmo que indiretamente, a criação do conhecimento. Em um terceiro estágio, os fatores relacionados ao conhecimento explícito já estão, na maioria das vezes, plenamente desenvolvidos, enquanto que os fatores relacionados ao conhecimento tácito estão em fase inicial de desenvolvimento. Em um quarto estágio, com os mecanismos relacionados ao conhecimento explícito já desenvolvidos, mecanismos relacionados a percepção e ao trabalho do conhecimento tácito encontram-se em desenvolvimento, para em um último estágio serem desenvolvidos, propiciando e possibilitando a articulação da gestão e da criação do conhecimentos, em seus diversos aspectos.

\section{Quadro 1 - Caracterização dos estágios propostos}

\section{Legenda:}

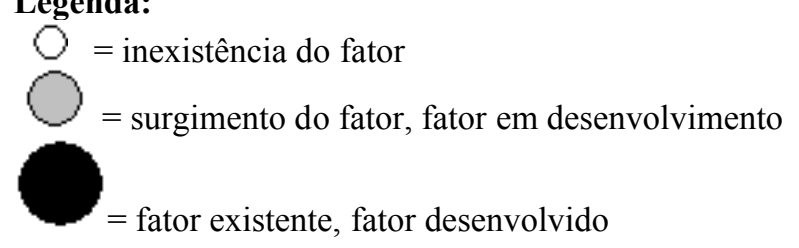

\begin{tabular}{|c|c|c|c|c|c|}
\hline Fatores & Estágio I & Estágio II & Estágio III & Estágio IV & Estágio V \\
\hline $\begin{array}{l}\text { sistematização das } \\
\text { informações }\end{array}$ & $\bigcirc$ & & & & \\
\hline comunicação formal & $\bigcirc$ & & & & \\
\hline trabalho em equipe & $\bigcirc$ & $\bigcirc$ & & & \\
\hline $\begin{array}{c}\begin{array}{c}\text { conhecimento } \\
\text { explícito }\end{array} \\
\end{array}$ & $\bigcirc$ & & & & \\
\hline conhecimento tácito & $\bigcirc$ & $\bigcirc$ & & & \\
\hline
\end{tabular}




\begin{tabular}{|c|c|c|c|c|c|}
\hline $\begin{array}{c}\text { disseminação do } \\
\text { conhecimento }\end{array}$ & $\bigcirc$ & $\bigcirc$ & $\bigcirc$ & $\bigcirc$ & \\
\hline $\begin{array}{c}\text { criação do } \\
\text { conhecimento }\end{array}$ & $\bigcirc$ & $\bigcirc$ & $\bigcirc$ & $\bigcirc$ & \\
\hline
\end{tabular}

Fonte: Autoria própria (2008)

\section{Considerações finais}

A relevância da identificação, definição e caracterização das fases ou estágios evolutivos da gestão do conhecimento na organização apresenta-se no conhecimento das necessidades e problemas da área em cada etapa de seu ciclo de vida organizacional possibilitando uso de ferramentas e ações de forma mais eficaz, sua evolução para a etapa subsequente e, consequentemente o desenvolvimento da gestão do conhecimento organizacional como um recurso competitivo através de um papel pró-ativo e da geração de vantagem competitiva à estratégia organizacional.

Essa relevância pode ser confirmada pelas diversas pesquisas, já realizadas, sobre os estágios evolutivos de diversas áreas funcionais da organização como o estudo feito por Hayes e Wheelwright (1984) sobre os estágios do desenvolvimento de produto e de processos de produção; a pesquisa realizada por Garvin (1992) que através de uma perspectiva histórica cita os estágios evolutivos da qualidade e; Bowersox (1986), que apresenta os estágios evolutivos da qualidade. Esses estudos comprovam a contribuição que a discussão e o estudo das áreas organizacionais através de suas fases ou estágios podem trazer com uma gestão mais eficiente da área e da organização em si. Assim, a relevância desse estudo fica evidenciada quando comparada às diversas áreas organizacionais, sejam elas áreas funcionais ou áreas do saber gerencial como a gestão do conhecimento, as quais já possuem estudos com esse foco e inclusive teorias com estágios bem definidos e caracterizados.

As limitações da pesquisa remetem a: os conceitos a respeito da criação do conhecimento que aqui foram baseados quase que única e exclusivamente na teoria de Nonaka e Takeuchi, devido a impossibilidade de tempo e espaço para adotar outras teorias, limitando a visão sobre o assunto; revisão teórica sobre as teorias de desenvolvimento da organização ou de suas áreas funcionais da organização, a qual é extensa e, por esse motivo, não pode ser completamente abordada e; ao ensaio teórico, através do qual foram trabalhadas apenas estruturas conceituais, não gerando, portanto dados empíricos sobre a evolução da gestão do conhecimento na prática das organizações.

Por esses motivos é importante que pesquisas futuras mais detalhadas tenham a possibilidade de aperfeiçoar uma concepção de estágios evolutivos para a gestão do conhecimento na organização. 


\begin{abstract}
The approach of functional areas through phases or stages of development enables managers to identify the maturity level of management that particular area is in organizational development in order to raise it to a status of a resource for generating competitive advantage pro-active participation in strategic management. The aim of this paper is to analyze the knowledge management through the design of their evolutionary stages in organizations, enabling its strategic role in generating competitive advantage. The result is presented a suggestion of evolutionary stages for knowledge management in organizations. The limitations of research address the fact that this is a theoretical research, through which were worked only conceptual frameworks, not generating, therefore, empirical data on the evolution of knowledge management practice in organizations. For these reasons it is important that more detailed future research should be able to perfect a conception of evolutionary stages for the management of knowledge in the organization.
\end{abstract}

Key-words: Knowledge management; Evolutionary stages; Organizational development.

\title{
Referências
}

ALBAGLI, S. Novos espaços de regulação na era da informação e do conhecimento. In: LASTRES, H. M. M., ALBAGLI, S. (org.) Informação e Globalização na era do conhecimento. 4 ed. Rio de Janeiro: Campus, 1999. Cap.11, p.290-313.

ALVARENGA NETO, R. C. D. de; BARBOSA, R. R.; PEREIRA, H. J. Gestão do conhecimento ou gestão de organizações da era do conhecimento? Um ensaio teórico-prático a partir de intervenções na realidade brasileira. Perspectivas em Ciência da Informação, v.12, n.1, p. 05-24, jan/abr 2007.

BASSANI, D. T. L.; NIKITIUK, S.; QUELHAS, O. A empresa como sede do conhecimento. Revista Produção, v. 13, n. 2, p. 42-56, 2003.

BOWERSOX, D. J et al. Logistical management: systems integration of physical distribution, manufacturing support and materials procurement. 1 ed. New York: Macmillan, 1986, p. 688.

CHEN, M.; CHEN, A. Knowledge management performance evaluation: a decade review from 1995 to 2004. Journal of Information Science, v.32, n.1, p.17-38, 2006.

cross ${ }^{\text {ref }}$

CRUZ, C. A.; NAGANO, M. S. Perfil evolutivo da teoria de criação do conhecimento organizacional. In: Simpósio de Engenharia de Produção - SIMPEP, XIII, 2004, Bauru. Anais... Bauru: UNESP, 2004, p.12. Disponível em: $<$ http://www.simpep.feb.unesp.br/simpep2007/upload/687.pdf>. Acesso em: 31 de mai. 2008.

DANTAS, M. Capitalismo na era das redes: trabalho, informação e valor no ciclo da comunicação produtiva. In: Informação e globalização na era do conhecimento. 4 edição. Rio de Janeiro: Campus, 1999, cap.9, p. 216-261.

DAFT, R. L. Organizações: teorias e projetos. São Paulo: Pioneira Thompson Learning, 2003, p. 532.

DAVENPORT, T. H.; PRUSAK, L. Conhecimento empresarial: como as organizações gerenciam o seu capital intelectual. Rio de Janeiro: Campus, 1998, p. 237.

DRUCKER, P. F. A sociedade pós-capitalista. 2 ed. São Paulo: Pioneira, 1993, p. 185.

EISENSTAT, R. A. What corporate human resources brings to the picnic: four models for functional management. Organizational Dynamics, v. 25, n. 2, p. 7-22, Autumn 1996.

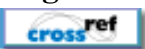

FERREIRA, F. H. G. A evolução de uma ciência chamada administração. 2003. Disponível em: $<$ http://www.biblioteca.sebrae.com.br/bds/BDS.nsf/C9E5FC7934D9146003256D520059B317/\$File/260_1_Arquivos_ adm.pdf $>$. Acesso em: 20 dez. 2009.

GARVIN, D. A. Gerenciando a qualidade: a visão estratégica e competitiva. Rio de Janeiro: Qualitymark, 1992. Caps.1 e 2, p. 3-45.

GREINER, L. Evolução e revolução no desenvolvimento das organizações. São Paulo: Abril Cultural, 1986. Coleção Harvard de Administração, n. 21. 
HAYES, R. H.; WHEELWRIGHT, S. C. Restoring our competitive edge: competing through manufacturing. $1^{\underline{a}}$ ed. New York: John Wiley, 1984. cap. 14, p. 391-410.

LEMOS, C. Inovação na era do conhecimento. In: LASTRES, H. M. M., LABAGLI, S. Informação e globalização na era do conhecimento. 4 ed. Rio de Janeiro: Campus, 1999. Cap. 5, p. 122-144.

MESHOULAM, I.; BAIRD, L. Proactive human resource management. Human Resource Management. v. 26, n. 4, p. 483-502, 1987.

MINTZBERG, H. Criando organizações eficazes: estruturas em cinco configurações. 1ª ed. São Paulo: Editora Atlas; 1995. p. 304.

NONAKA, I.; TAKEUCHI, H. Criação de conhecimento na empresa. 12 ed. Rio de Janeiro: Editora Campus, 1997. p. 358.

PRUSAK, L. Where did knowledge management come from? IBM Systems Journal, v. 40, n. 4, p. 1002-1007, 2001.

\section{cross ${ }^{\text {ref }}$}

RODRIGUES, E. A.; SANTOS, F. C. A. Os estágios evolutivos do conhecimento, da tecnologia e da informação como elementos do capital intelectual. In: Simpósio de Engenharia de Produção - SIMPEP, XI, 2006, Bauru. Anais... Bauru: UNESP, 2006, p. 12. Disponível em:

<http://www.simpep.feb.unesp.br/simpep2007/Anais\%20XI\%20SIMPEP_Arquivos/07.php>. Acesso em: $11 \mathrm{de}$ mai. 2008.

SANTOS, F. C. A. Integration of human resource management and competitive priorities of manufacturing strategy. International Journal of Operations \& Production Management, v. 20, n. 5, p. 610-628, 2000.

cross ref

SANTOS, F. C. A. Similaridades dos estágios evolutivos das áreas de gestão. Revista de Administração (RA-USP). v. 36, n. 4, p. 18-32, out./dez. 2001.

SCHULER, R. S.; JACKSON, S. E. Linking competitive strategies with human resource management. In: MINER, J. B.; CRANE, D. P. (coord.) Advances in the practice, theory and research of strategic human resource management. New York, Harper Collins, 1995. cap. 2, p. 20-40.

TERRA, J. C. C. Gestão do conhecimento para o Brasil. Disponível em: < http:// www.terraforum.com.br>. Acesso em: 10 de abr. 2008.

TERRA, J. C. C. et al. Espaços de trabalho na era do conhecimento. Disponível em: $<\mathrm{http}$ ://www.terraforum.com.br>. Acesso em: 31 de abr. 2008.

WIIG, K.M. Knowledge management: an emerging discipline rooted in a long history. In: Despres, C., Chauvel, D. (Ed.) Knowledge Horizons: The Present and the Promise of Knowledge Management. Butterworth-Heinemann, New York, 2000. Cap. 1, p. 3-23.

WREN, K. M. The evolution of management thought. 4 ed. New York: John Wiley \& Sons, 1994. p. 466.

ZUBOFF, S. Automatizar / informatizar: as duas faces da tecnologia inteligente. Revista de Administração de Empresas - RAE. São Paulo: FGV, v. 34, n. 6, nov/dez 1994. p. 80-91.

\section{Nome completo: Giovana Escrivão}

Filiação institucional: Universidade de São Paulo

Departamento: Departamento de Engenharia de Produção

Função ou cargo ocupado: mestranda

Endereço completo para correspondência (bairro, cidade, estado, país e CEP): Av. Trabalhador Sãocarlense, 400 - Centro - CEP 13566-590 - São Carlos/SP, Brasil 
Telefones para contato: (16) 33738126

e-mail:giescrivao@uol.com.br

Nome completo: Marcelo Seido Nagano

Filiação institucional: Universidade de São Paulo

Departamento: Departamento de Engenharia de Produção

Função ou cargo ocupado: Professor Doutor

Endereço completo para correspondência (bairro, cidade, estado, país e CEP): Av. Trabalhador Sãocarlense, 400 - Centro - CEP 13566-590 - São Carlos/SP, Brasil

Telefones para contato: (16) 33738126

e-mail:drnagano@usp.br

Nome completo: Charbel José Chiappetta Jabbour

Filiação institucional: Universidade de São Paulo

Departamento: Departamento de Administração

Função ou cargo ocupado: Professor Doutor

Endereço completo para correspondência (bairro, cidade, estado, país e CEP): Av. Bandeirantes, 3900 - Monte Alegre - CEP 14040-900 - Ribeirão Preto/SP, Brasil

Telefones para contato: (16) 3602-4746

e-mail:charbel@usp.br

Enviado em: 22/02/2010

Aprovado em:02/03/2011 